\title{
Photo-Fenton and Fenton Oxidation of Recalcitrant Industrial Wastewater Using Nanoscale Zero-Valent Iron
}

\author{
Henrik Hansson, ${ }^{1}$ Fabio Kaczala, ${ }^{1}$ Marcia Marques, ${ }^{1,2}$ and William Hogland ${ }^{1}$ \\ ${ }^{1}$ School of Natural Sciences, Linnaeus University (LNU), Landgången 3, 39282 Kalmar, Sweden \\ ${ }^{2}$ Department of Sanitary and Environmental Engineering, Rio de Janeiro State University (UERJ), \\ São Francisco Xavier 524, 20551-013 Rio de Janeiro, RJ, Brazil \\ Correspondence should be addressed to Marcia Marques, marcia.marques@lnu.se
}

Received 1 June 2012; Revised 20 August 2012; Accepted 7 September 2012

Academic Editor: Manickavachagam Muruganandham

Copyright (c) 2012 Henrik Hansson et al. This is an open access article distributed under the Creative Commons Attribution License, which permits unrestricted use, distribution, and reproduction in any medium, provided the original work is properly cited.

There is a need for the development of on-site wastewater treatment technologies suitable for "dry-process industries," such as the wood-floor sector. Due to the nature of their activities, these industries generate lower volumes of highly polluted wastewaters after cleaning activities. Advanced oxidation processes such as Fenton and photo-Fenton, are potentially feasible options for treatment of these wastewaters. One of the disadvantages of the Fenton process is the formation of large amounts of ferrous iron sludge, a constraint that might be overcome with the use of nanoscale zero-valent iron (nZVI) powder. Wastewater from a wood-floor industry with initial COD of $4956 \mathrm{mg} / \mathrm{L}$ and TOC of $2730 \mathrm{mg} / \mathrm{L}$ was treated with dark-Fenton $\left(\mathrm{nZVI} / \mathrm{H}_{2} \mathrm{O}_{2}\right)$ and photo-Fenton (nZVI/ $\mathrm{H}_{2} \mathrm{O}_{2} / \mathrm{UV}$ ) applying a 2-level full-factorial experimental design. The highest removal of COD and TOC ( $80 \%$ and $60 \%$, resp.) was achieved using photo-Fenton. The supply of the reactants in more than one dose during the reaction time had significant and positive effects on the treatment efficiency. According to the results, Fenton and mostly photo-Fenton are promising treatment options for these highly recalcitrant wastewaters. Future investigations should focus on optimizing treatment processes and assessing toxic effects that residual pollutants and the nZVI might have. The feasibility of combining advanced oxidation processes with biological treatment is also recommended.

\section{Introduction}

The discharge of industrial wastewaters into either municipal sewerage system or directly into recipient water bodies has raised serious concerns during decades, leading to intensive research and development of on-site treatment technologies for industrial wastewater. However, whereas investigations have been focusing on industrial sectors that have water as an important input to their manufacturing processes, "dry-process industries" such as wood-floor and woodfurniture industries that have no water requirement in their production processes have been neglected $[1,2]$. These industries generate wastewaters during cleaning and washing of machinery, surfaces, and floors and regardless of their relatively low volumes these cleaning wastewaters have very high chemical oxygen demand (COD) that varies from 3200 to $50,000 \mathrm{mg} \mathrm{L}^{-1}$ and the presence of recalcitrant organic compounds is a limiting factor for biological treatment in conventional centralized treatment plants. Dilution of 50 times or more with drinking water has been a common practice before discharging these wastewaters into the sewage system, which is not a sustainable strategy for the 21st century. The treatment of wastewaters from the timber industry using chemical methods has shown limited efficiency [3]. The use of biological treatment [1] and sorption/filtration processes [2] has also shown limitations when the main purpose is to comply with established standards for discharges into recipient water bodies. Advanced oxidation processes (AOPs) have previously been used to treat complex wastewaters in combinations with biological and/or chemical treatment. These studies have used AOP either after biological treatments to handle the most recalcitrant substances $[4,5]$ or before with the purpose of reducing toxicity, when the wastewater is too toxic for biological 
treatment $[6,7]$. The Fenton reaction was first observed by $\mathrm{H}$. J. Fenton in 1894 and is described as the enhanced oxidative power of $\mathrm{H}_{2} \mathrm{O}_{2}$ when using iron $(\mathrm{Fe})$ as a catalyst under acidic conditions. It was later found that this enhancement was due to the generation of hydroxyl radical $\left(\mathrm{HO}^{\bullet}\right)$ [8] that is one of the strongest oxidants $(\mathrm{E}=2.73 \mathrm{~V})$, and it is nonselective and capable of quickly oxidizing a broad range of organic pollutants [9]. AOPs are based on the generation of these very reactive species, which are the main oxidizing species in the Fenton process [10]. The Fenton's reagent alone or in combination has proven to be an effective way to degrade organic pollutants [11-13] and it has been used for the treatment of a wide variety of industrial wastewaters [14-16]. The Fenton process is a relatively economical method since it requires no additional energy when compared to many other AOPs. Furthermore, both iron and hydrogen peroxide are relatively cheap and safe. In the Fenton process, there is no mass transfer limitation, except during coagulation when high dose of the activator ferrous salt is needed [17]. The Fenton process is well known [18]. Iron (Fe) will in aqueous solution under acidic conditions oxidize to $\mathrm{Fe}^{2+}[19]$, which initiates the Fenton reaction:

$$
2 \mathrm{Fe}^{0}+2 \mathrm{H}_{2} \mathrm{O} \longrightarrow \mathrm{Fe}^{2+}+\mathrm{H}_{2}+2 \mathrm{OH}^{-}
$$

The Fenton reaction is characterized by the catalytic decomposition of $\mathrm{H}_{2} \mathrm{O}_{2}$ as described below [20]:

$$
\mathrm{Fe}^{2+}+\mathrm{H}_{2} \mathrm{O}_{2} \longrightarrow \mathrm{Fe}^{3+}+\mathrm{OH}^{-}+\mathrm{OH}^{\bullet}
$$

The hydroxyl radicals created by the process can be scavenged by excess $\mathrm{Fe}^{2+}[20]$ :

$$
\mathrm{OH}^{\bullet}+\mathrm{Fe}^{2+} \longrightarrow \mathrm{OH}^{-}+\mathrm{Fe}^{3+}
$$

This conventional Fenton process may be positively assisted by the application of UV-light [20]:

$$
\mathrm{Fe}^{3+}+\mathrm{H}_{2} \mathrm{O}+h v \longrightarrow \mathrm{OH}^{\bullet}+\mathrm{Fe}^{2+}+\mathrm{H}^{+}
$$

Photo-Fenton oxidation in the presence of short UV light (UV-C, 180-290 nm) [21] gives a faster oxidation as a consequence of the higher quantum yields [12]. When applying UV-C light, $\mathrm{H}_{2} \mathrm{O}_{2}$ can also be hydrolysed contributing to the $\mathrm{HO}^{\circ}$ formation [8]. The disadvantages of the Fenton process include (i) the formation of a high concentration of anions in the treated wastewater and (ii) large amounts of ferrous iron sludge [22]. Recent studies have attempted to overcome these drawbacks by applying nZVI together with $\mathrm{H}_{2} \mathrm{O}_{2}$ for industrial wastewater treatment $[19,23]$. This alternative process could overcome the disadvantages associated with $\mathrm{Fe}^{2+}$-based AOPs by using the solid form of iron instead of $\mathrm{Fe}^{2+}$ as iron salts. During the last decade there has been a widespread development of nanomaterials for both industrial and domestic use. When the dimensions of a piece of solid material become very small, its physical and chemical properties become very different from those of the same material in larger bulk form [24]. Nanoparticles as a subset of nanomaterial is currently defined by consensus
TABLE 1: Wastewater characterization $(n=3)$.

\begin{tabular}{lcc}
\hline Parameter & Value & Mixture* $^{*}$ \\
\hline $\mathrm{pH}$ & $2.3 \pm 0.5$ & 2.2 \\
Conductivity $(\mathrm{mS} / \mathrm{cm})$ & $6.3 \pm 0.6$ & 5.9 \\
$\mathrm{COD}(\mathrm{mg} / \mathrm{L})$ & $5102 \pm 513$ & 4956 \\
TOC $(\mathrm{mg} / \mathrm{L})$ & $2,801 \pm 287$ & 2730 \\
\hline
\end{tabular}

* Wastewater obtained from a mixture of these three characterized samples.

as single particles with a diameter $<100 \mathrm{~nm}$ [24]. The small particle size increases the proportion of atoms located at the surface increasing the possibility for the atoms to adsorb, interact, and react with other atoms and molecules [25]. The particles have also the capacity to remain in suspension [25] and, hence, aqueous slurries containing nZVI can easily be pumped and injected where needed. The nZVI has been mostly used for groundwater remediation and treatment of specific pollutants [25]. Additionally, the treatment of industrial wastewater using nZVI in Fenton and other processes has also been reported recently [26, 27].

The main objective of this investigation was two-folded: (i) to verify the technical feasibility of treating wastewaters generated in the wood-floor industry sector using Fenton with nZVI compared to photo-Fenton with nZVI and (ii) to verify the effects of the selected variables $\left(\mathrm{H}_{2} \mathrm{O}_{2} / \mathrm{COD}\right.$ ratio, $\mathrm{H}_{2} \mathrm{O}_{2} / \mathrm{nZVI}$ ratio and dosing mode) on the treatment efficiency.

\section{Materials and Methods}

2.1. Wastewater Samples. The wastewater used in the current investigation was a mixture of different streams of real industrial wastewater generated during cleaning procedures in a wood-floor industry in Nybro, Sweden. The quality and quantity of these wastewaters vary in time, as they are manually and intermittently generated as a consequence of different manufacturing processes such as wood gluing, wood filling, cleaning of floors, blade sharpening, and others. These wastewaters are characterized by the presence of formaldehyde, nitrogen [1], metals [28] detergents, and, phenols [29]. At the factory, the wastewater mixture is kept in a full-scale on-site settling/sedimentation tank from where the samples for lab studies were taken. Wastewater samples were obtained at three different occasions and transported to the laboratory where they were stored at $-20^{\circ} \mathrm{C}$.

In order to obtain an average composition of the wastewater, a mixture of similar proportion of the three samples stored in the lab $(1: 1: 1)$ was prepared. This mixture was then filtered with a Munktell OOR grade filter paper with a pore size $>10 \mu \mathrm{m}$ to homogenize the wastewater. The characteristics of the wastewater used in the experiments are shown in Table 1. Proxy indicators such as TOC and COD were considered suitable to monitor treatability studies of this wastewater, since it is well known that these variables as well as the ratio between them are appropriate to evaluate the efficiency of treatment options [30, 31]. 
TABLE 2: Variable levels applied in the 2-level factorial design.

\begin{tabular}{lcccc}
\hline Variables & Symbol & -1 & 0 & +1 \\
\hline $\mathrm{H}_{2} \mathrm{O}_{2}:$ COD & $\chi_{1}$ & $2: 1$ & $3.5: 1$ & $5: 1$ \\
$\mathrm{H}_{2} \mathrm{O}_{2}:$ nZVI & $\chi_{2}$ & $2: 1$ & $8.5: 1$ & $15: 1$ \\
Dosing mode & $\chi_{3}$ & 1 & 2 & 3 \\
\hline
\end{tabular}

Notations: +1 (high level); 0 (centre point); -1 (lower level).

2.2. Experimental Design. To have a better understanding on which independent variables play important roles on the treatment efficiency measured as percentage reduction of COD and TOC (dependent variables), it was applied a twolevel full-factorial design with triplicates of the central points with the following selected independent variables or factors: (1) $\mathrm{H}_{2} \mathrm{O}_{2}$ : COD ratio; (2) $\mathrm{H}_{2} \mathrm{O}_{2}$ :nZVI ratio and; (3) the dosing mode. By dosing mode one means the procedure of adding equal aliquots of the oxidizing agent $\left(\mathrm{H}_{2} \mathrm{O}_{2}\right)$ and the catalyst (nZVI) at different times throughout the experiment or adding it at once. The levels used for each factor in this investigation (Table 2) were selected according to the literature.

The AOS (average oxidation state) value was calculated using the COD and TOC data obtained by the abovedescribed experimental design. The AOS value can attain a value between +4 , for $\mathrm{CO}_{2}$, and -4 , for $\mathrm{CH}_{4}$, the most oxidized and the most reduced state of carbon (C). The AOS value is a rough parameter to estimate the degree of oxidation in a mixed wastewater and was calculated according to the following [31]:

$$
\mathrm{AOS}=\frac{4(\mathrm{TOC}-\mathrm{COD})}{\mathrm{TOC}}
$$

where COD and TOC values are expressed in $\mathrm{mol} \mathrm{O}_{2} / \mathrm{L}$ and $\mathrm{C} / \mathrm{L}$, respectively.

The statistical software Minitab 16 was used to setup the full factorial design. For statistical analysis Minitab 16 and GraphPad Prism 5 were used.

2.3. Experimental Setup. Two variations of Fenton treatment were investigated: dark-Fenton $\left(n \mathrm{nVI} / \mathrm{H}_{2} \mathrm{O}_{2}\right)$ and photoFenton (nZVI/ $\left.\mathrm{H}_{2} \mathrm{O}_{2} / \mathrm{UV}\right)$, using, in both cases, commercial nZVI. The commercial nZVI powder consisted of $\mathrm{Fe}^{0}$ surface stabilized nanoparticles coated with a thin inorganic surface layer, which makes it possible long-term storage as the manufacturer delivers it. The material had particle sizes ranging between $20-100 \mathrm{~nm}$ with an average of $50 \mathrm{~nm}$ according to the manufacturer (Nano Iron, s.r.o., Czech Republic). The photo-Fenton studies were carried out in a glass-jacket immersion-type UV-reactor (UV-Consulting Peschl Mainz, Germany) with a volume of $0.7 \mathrm{~L}$ (Figure 1). The distance between the UV-lamp and the liquid phase was $15 \mathrm{~mm}$. The reactor was cooled down with distilled water to keep the liquid phase at room temperature of around $22^{\circ} \mathrm{C}$. The UV-light was emitted at a $150 \mathrm{~W}$ in wavelengths ranging between 250 and $580 \mathrm{~nm}$ with the highest peaks at 310, 360, $400,440,550$, and $580 \mathrm{~nm}$.

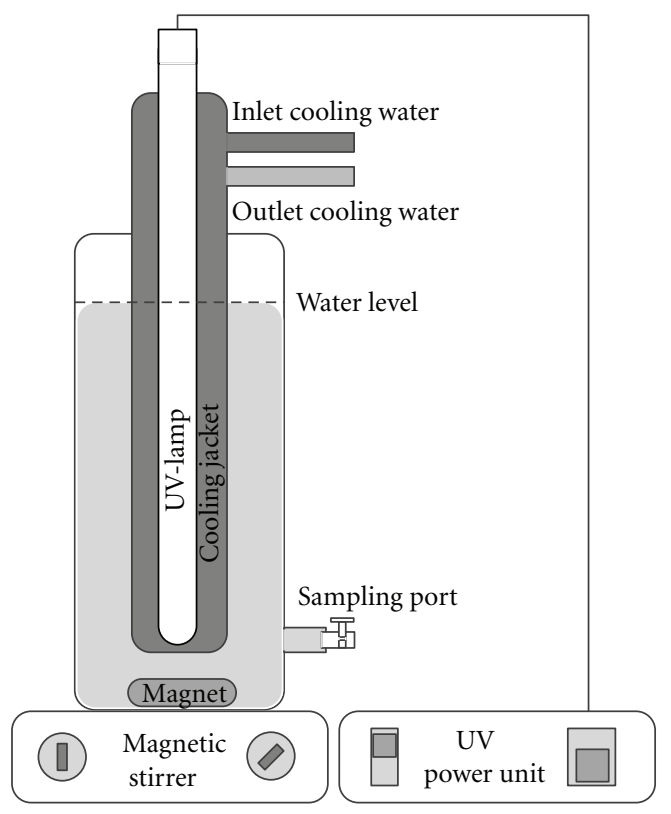

Figure 1: Schematic view of the UV-reactor used in the photoFenton experiments.

The dark-Fenton studies were conducted in $1 \mathrm{~L}$ glass beakers. The difference between standard glass beaker and the UV-reactor with the light in the off-mode was considered negligible according to the literature $[32,33]$. Air purging was not considered in this study in order to keep treatment operational costs as low as possible. All glassware was carefully washed before each experiment.

2.4. Experimental Procedure. All runs were conducted with a volume of $0.5 \mathrm{~L}$ of wastewater that was agitated during $120 \mathrm{~min}$ by a magnetic stirrer at $400 \mathrm{rpm}$. The $\mathrm{pH}$ was adjusted at the beginning of each run to be kept between 2.95 and 3.05. Since this $\mathrm{pH}$ range has been reported to be the optimum for Fenton oxidation [13, 34], every $15 \mathrm{~min}$ throughout the $120 \mathrm{~min}$ of reaction time the $\mathrm{pH}$ was readjusted if needed. All pH adjustments were done with analytical grade sodium hydroxide $(\mathrm{NaOH})$ and hydrochloric acid $(\mathrm{HCl})$. The total amounts of nZVI and $\mathrm{H}_{2} \mathrm{O}_{2}$ were added either at the beginning of each run or in similar aliquots, at different time intervals (Table 3 ). The nZVI was added as slurry formed by $1: 4 \mathrm{nZVI}$ powder and water, after being stirred in a high speed sheerer for $5 \mathrm{~min}$, according to the manufacturer's instructions.

During the photo-Fenton treatment, the wastewater was exposed to UV-light during the treatment time of $120 \mathrm{~min}$. After both Fenton and photo-Fenton treatments of $120 \mathrm{~min}$, the $\mathrm{pH}$ of the wastewater was adjusted to 6.5 and agitated for $5 \mathrm{~min}$ at $400 \mathrm{rpm}$ to quench the Fenton reaction [35]. In a sequence, $5 \mathrm{~min}$ after the agitation was stopped, the $\mathrm{pH}$ was raised to 8.5 to form iron precipitates [35]. The supernatant was then heated to $50^{\circ} \mathrm{C}$ and slowly shaken in a water bath for 30 min to expel any remaining $\mathrm{H}_{2} \mathrm{O}_{2}$. The water was then 


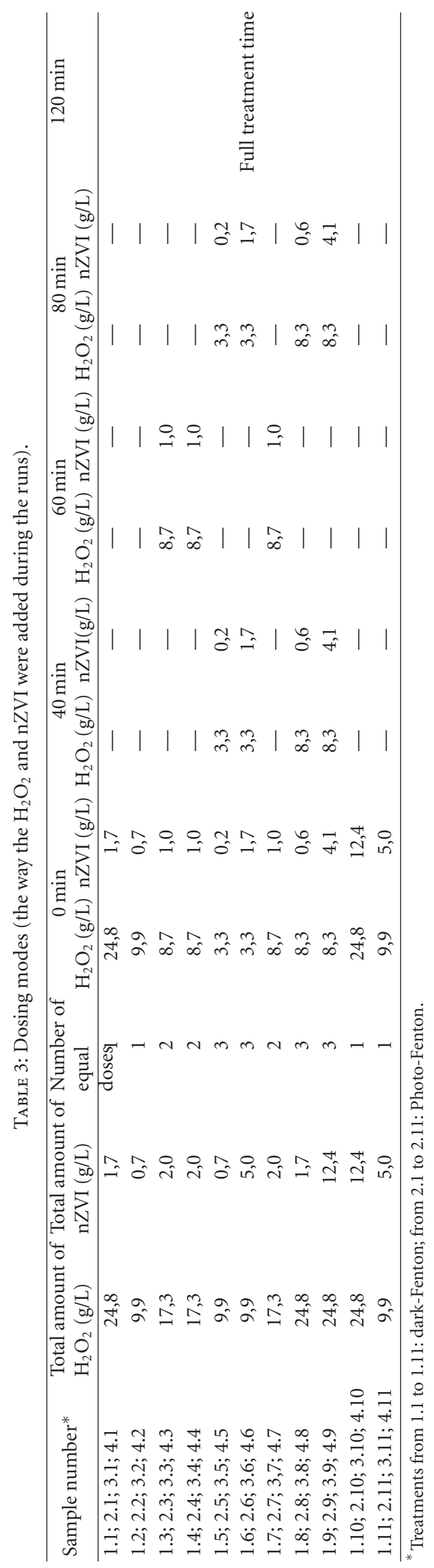


TABLE 4: COD and TOC reductions (\%) with dark-Fenton and photo-Fenton experiments.

\begin{tabular}{|c|c|c|c|c|c|c|c|c|}
\hline \multicolumn{3}{|c|}{ Coded variables } & \multicolumn{4}{|c|}{ Dark-Fenton } & \multicolumn{2}{|c|}{ Photo-Fenton } \\
\hline$\chi_{1}$ & $\chi_{2}$ & $\chi_{3}$ & Run & $\%$ COD reduction & $\%$ TOC reduction & Run & $\%$ COD reduction & $\%$ TOC reduction \\
\hline+1 & +1 & -1 & 1.1 & 42.6 & 21.4 & 2.1 & 78.4 & 59.4 \\
\hline-1 & +1 & -1 & 1.2 & 34.6 & 17.3 & 2.2 & 70.6 & 50.0 \\
\hline 0 & 0 & 0 & 1.3 & 42.0 & 21.4 & 2.3 & 80.5 & 57.8 \\
\hline 0 & 0 & 0 & 1.4 & 39.3 & 19.9 & 2.4 & 78.2 & 56.7 \\
\hline-1 & +1 & +1 & 1.5 & 35.6 & 19.0 & 2.5 & 77.6 & 56.0 \\
\hline-1 & -1 & +1 & 1.6 & 35.1 & 18.9 & 2.6 & 76.1 & 53.9 \\
\hline 0 & 0 & 0 & 1.7 & 38.4 & 24.2 & 2.7 & 61.3 & 61.7 \\
\hline+1 & +1 & +1 & 1.8 & 43.5 & 23.0 & 2.8 & 60.3 & 61.7 \\
\hline+1 & -1 & +1 & 1.9 & 77.5 & 50.3 & 2.9 & 81.6 & 61.6 \\
\hline+1 & -1 & -1 & 1.10 & 49.2 & 34.9 & 2.10 & 78.5 & 58.0 \\
\hline-1 & -1 & -1 & 1.11 & 38.3 & 24.7 & 2.11 & 70.9 & 53.6 \\
\hline
\end{tabular}

centrifuged at $614 \mathrm{~g}$ for $15 \mathrm{~min}$. After this, the supernatant was separated and all samples were frozen before analysis.

2.5. Analytical Methods. COD and TOC in the wastewater samples were analysed spectrophotometrically using Hach Lange cuvette tests (Hach Lange, Dusseldorf) and measured with a Hach Lange DR 5000 spectrophotometer (Hach Lange, Dusseldorf). The $\mathrm{pH}$ and conductivity were measured with an HQ40d multiparameter meter.

\section{Results and Discussion}

\subsection{Comparison between Fenton and Photo-Fenton}

3.1.1. nZVI Fenton Treatment. The treatments based on dark-Fenton (Table 4 and Figures 2(a) and 2(b)) showed large variation in the responses measured as the COD and TOC removal percentages. As observed in Table 4, the removal of COD and TOC varied from $34 \%$ to $77 \%$ and from $17 \%$ to $50 \%$, respectively, depending on the run indicating that the ranges of $\mathrm{H}_{2} \mathrm{O}_{2}: \mathrm{COD} ; \mathrm{H}_{2} \mathrm{O}_{2}$ :nZVI and dosing modes combined in different ways have played an important role on the COD and TOC removal. There was a significant difference between COD and TOC reduction \% within the dark-Fenton and photo-Fenton processes (paired $t$-test, $P<$ 0.05 ) as illustrated in Table 4.

The highest reductions for both COD and TOC were achieved with a setup using high $\mathrm{H}_{2} \mathrm{O}_{2}$ : COD ratios and low $\mathrm{H}_{2} \mathrm{O}_{2}$ :nZVI ratio (run 1.9 in Table 4 and 9 in Figure 2(a)), indicating that higher concentrations of the oxidizing agent $\left(\mathrm{H}_{2} \mathrm{O}_{2}\right)$ and the catalyst were able to oxidize a higher amount of COD and TOC, despite the fact that high concentrations of nZVI will possibly scavenge hydroxyl radicals. The stoichiometric ratio for the reduction of COD by $\mathrm{H}_{2} \mathrm{O}_{2}$ is 2.125 which is calculated assuming the complete oxidation of COD [36]:

$$
\begin{aligned}
1 \mathrm{~g} \mathrm{COD} & =1 \mathrm{~g} \mathrm{O}_{2}=0.03125 \mathrm{~mol} \mathrm{O}_{2} \\
& =0.0625 \mathrm{~mol} \mathrm{H}_{2} \mathrm{O}_{2}=2.125 \mathrm{~g} \mathrm{H}_{2} \mathrm{O}_{2},
\end{aligned}
$$

(see $[36])$.
The results have shown that the amount of $\mathrm{H}_{2} \mathrm{O}_{2}$ to achieve the best treatment efficiency was twice as much the amounts stoichiometrically required. However such occurrences can be due to several factors that need to be further investigated. An important aspect regarding the Fenton treatment is the reduction of $\mathrm{Fe}^{3+}$ to $\mathrm{Fe}^{2+}$ making crucial the presence of reaction intermediates able to reduce $\mathrm{Fe}^{3+}$ and regenerate the catalyst. However, there are reaction intermediates that instead of reducing the $\mathrm{Fe}^{3+}$ remove it from the $\mathrm{Fe}^{2+} / \mathrm{Fe}^{3+}$ cycle, due to the generation of iron complexes, delaying and/or inhibiting the oxidation process [18]. Regardless the use of higher amounts of $\mathrm{H}_{2} \mathrm{O}_{2}$ in comparison to the stoichiometric need, the $\mathrm{H}_{2} \mathrm{O}_{2}$ : COD ratio of $5: 1$ was in a range similar to that reported as being effective in previous studies $[14,18]$. On the other hand the $\mathrm{H}_{2} \mathrm{O}_{2}$ : nZVI ratio of 2:1 was lower than the values found in literature $[12,18,37]$.

When analysing the amount of oxidizing agent $\mathrm{H}_{2} \mathrm{O}_{2}$ per unit of COD removed $\left(\mathrm{g} \mathrm{H}_{2} \mathrm{O}_{2} / \mathrm{g} \mathrm{COD}\right.$ removed) used in different treatments in Figure 2(b), other treatments can be considered economically more feasible (runs 1.2, 1.5, 1.6, and 1.11 in Table 4; respectively 2, 5, 6, and 11 in Figure 2(b)). But run 1.9 was much more efficient in terms of COD removal and it was not considerably worse than the others above mentioned regarding $\mathrm{g}_{2} \mathrm{O}_{2} /$ g COD removed.

3.1.2. nZVI Photo-Fenton Treatment. The results regarding COD and TOC removals with photo-Fenton have shown that the addition of the UV energy has significantly increased the treatment efficiency compared to dark-Fenton (paired $t$-test, $P<0.05$ ) (Figures 3(a) and 3(b)). Furthermore, it was observed that during the photo-Fenton process, the reductions of COD and TOC were more homogenous in comparison to those observed for the dark-Fenton treatment (Table 4; Figures 2(c) and 2(d)).

The increase of TOC reduction was significantly higher than the increase of COD reduction by photo-Fenton (Figure 3(c)). A significant difference was observed between the reductions (in \%) of COD and TOC with photo-Fenton treatment (paired $t$-test, $P<0.05$ ). 


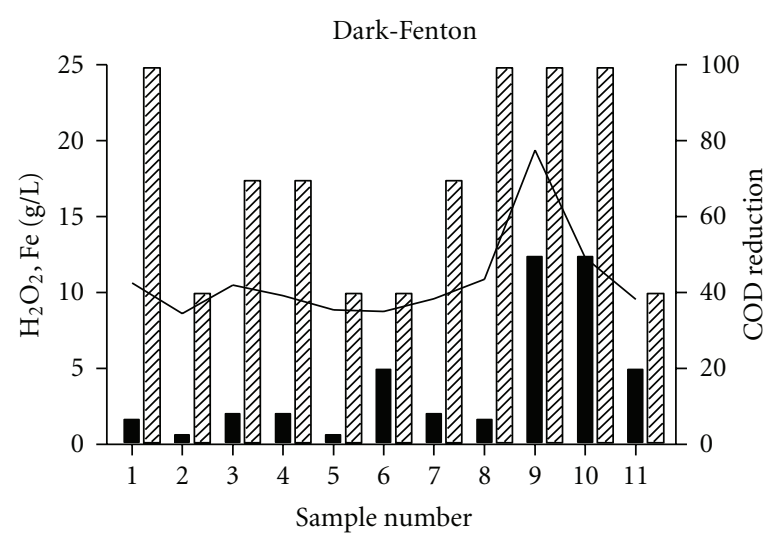

(a)

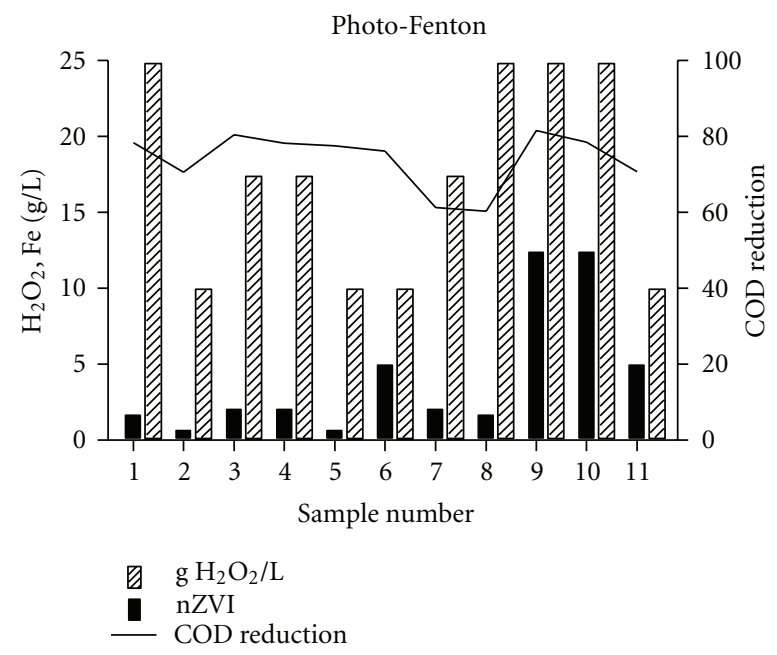

(c)

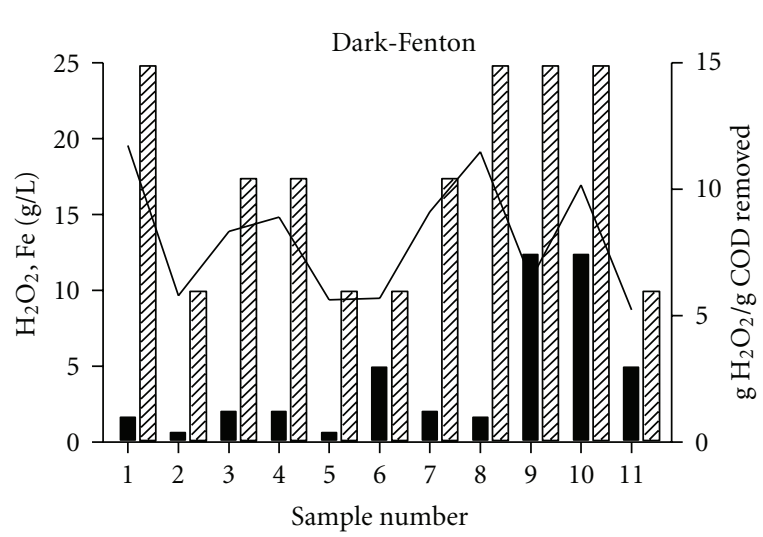

(b)

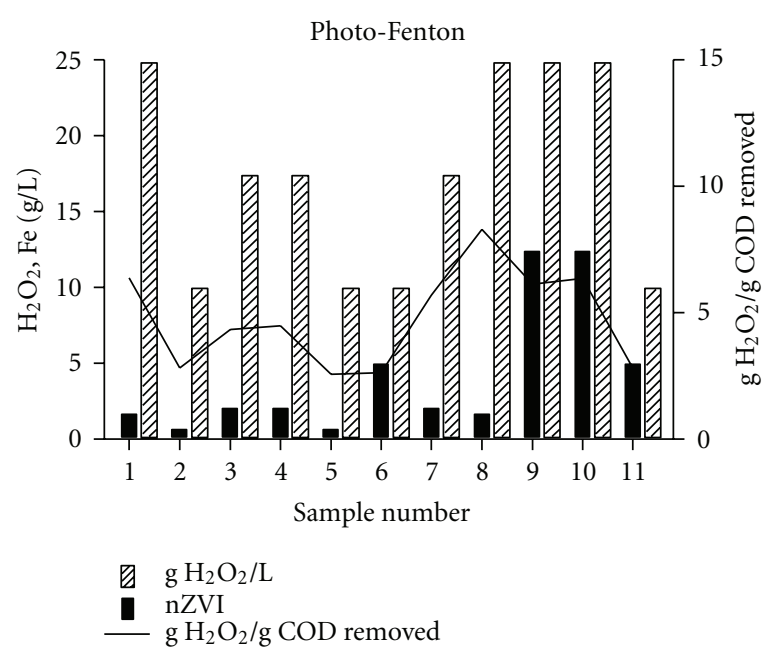

(d)

FIGURE 2: Results from dark-Fenton (a) and (b) and photo-Fenton (c) and (d) experiments using nZVI in 11 runs each. (a) and (c) Amounts of reagents (g/L) and COD removal (\%); (b) and (d) amounts of reagents $(\mathrm{g} / \mathrm{L})$ and $\mathrm{g}_{2} \mathrm{O}_{2}$ consumed per g COD removed.

Run 2.9 in Table 4 (equivalent to 9 in Figure 2(c)) promoted the highest removal of COD and TOC in \%. However, when taking into account the amount of oxidizing agent used per amount of COD removed $\left(\mathrm{g} \mathrm{H}_{2} \mathrm{O}_{2} / \mathrm{g} \mathrm{COD}\right.$ removed), another treatment was economically more effective (run 2.5 in Table 4, equivalent to run 5 in Figure 2(d)). In Figure 2, both runs 5 and 6 performed satisfactorily and with low amounts of $\mathrm{H}_{2} \mathrm{O}_{2}$ promoted COD removals of around $80 \%$, indicating the crucial role played by the UV energy in terms of treatment efficiency. The efficiency in using the UV in combination with the Fenton reaction is confirmed in Figures 2(c) and 2(d), which illustrate that despite using a $\mathrm{H}_{2} \mathrm{O}_{2}$ : $\mathrm{COD}$ ratio as high as 5:1 in run 2.9 (Table 4), only a small increase in COD removal in \% was observed compared to runs 2.5 and 2.6 (Table 4) where a $\mathrm{H}_{2} \mathrm{O}_{2}$ : $\mathrm{COD}$ ratio of only $2: 1$ was used. COD and TOC reductions over $75 \%$ and $55 \%$, respectively, were achieved in runs 2.5 and 2.6 (Table 4), respectively, which corresponded to less than half of the amount of $\mathrm{H}_{2} \mathrm{O}_{2}$ applied in run 2.9 (COD and TOC reductions of $82 \%$ and $61 \%$, resp.). Similar results were reported [38] where an increase of $\mathrm{H}_{2} \mathrm{O}_{2}$ : $\mathrm{COD}$ ratio above the range of 1-3 did not improve the COD reduction related to the presence of antibiotics in the water. Furthermore, the use of high concentrations of nZVI in runs 2.6 and 2.9 $\left(\mathrm{H}_{2} \mathrm{O}_{2}\right.$ :nZVI of $2: 1$, Table 4) did not result in a increased efficiency, in comparison to run $2.5\left(\mathrm{H}_{2} \mathrm{O}_{2}\right.$ : nZVI of $\left.15: 1\right)$. As discussed previously, one important event for the Fenton process is the reduction of $\mathrm{Fe}^{3+}$ to $\mathrm{Fe}^{2+}$ and such reduction is enhanced when using photo-Fenton [20]. This is likely one of the reasons for the much larger reductions in general achieved with photo-Fenton, being another reason for the fact that significantly lower concentrations of nZVI can be used. It is worth noting that in all these setups the reactants were added in three doses along the treatment, reducing the risk for scavenging between the reactants. Figure 2(d) shows that when $94 \%$ less nZVI was used, only $6 \%$ less COD and TOC reductions were observed in the presence of UV. Such a large reduction of iron reduces the costs with this catalyst and the amount of spent iron that needs to be handled (see the discussion Cost Effectiveness in this paper). 


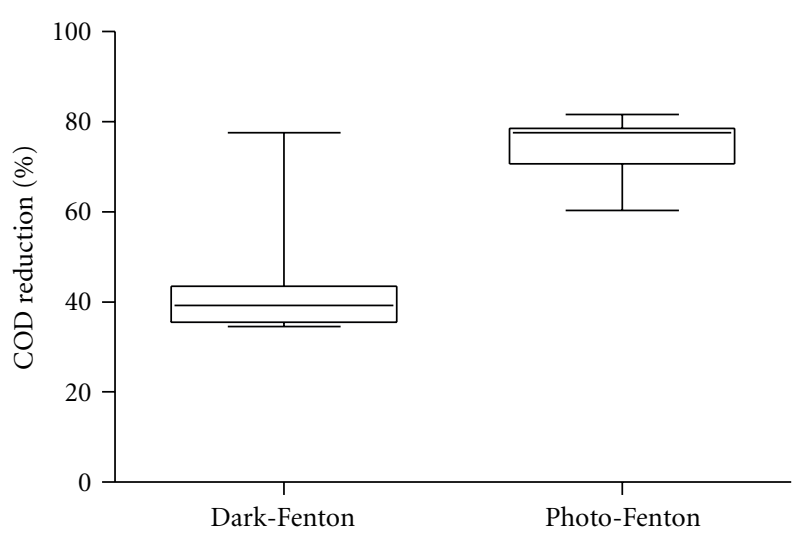

(a)

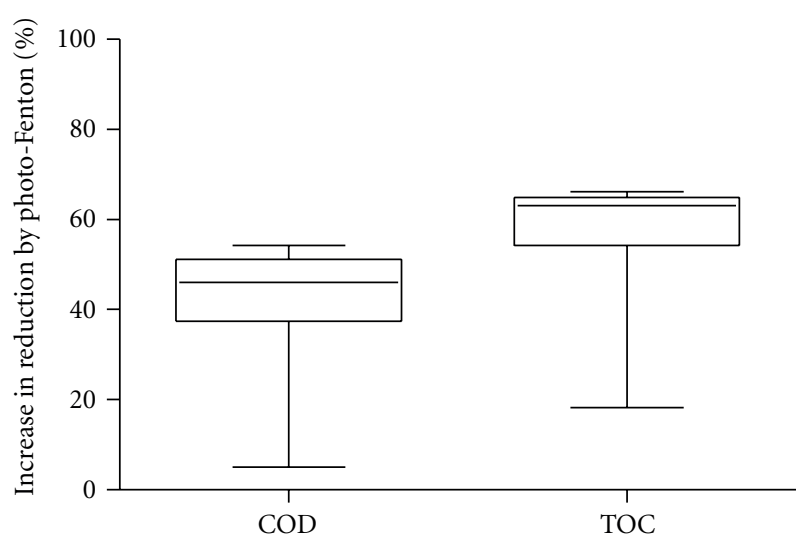

(c)

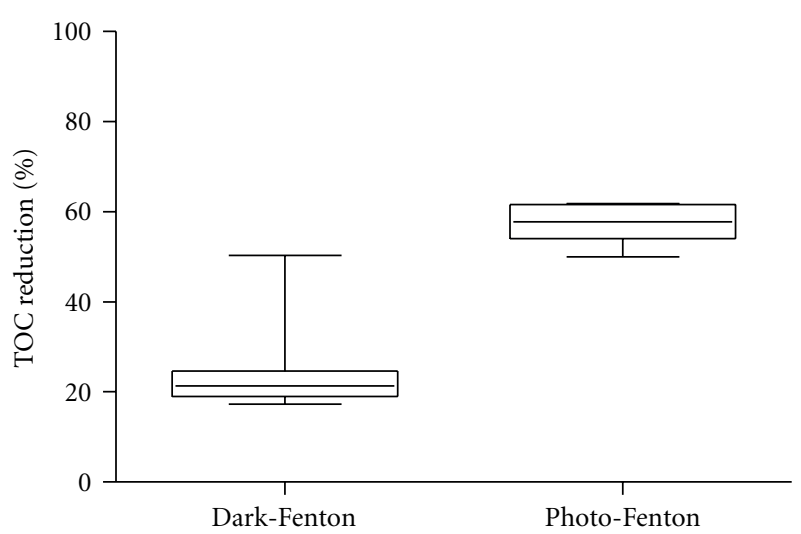

(b)

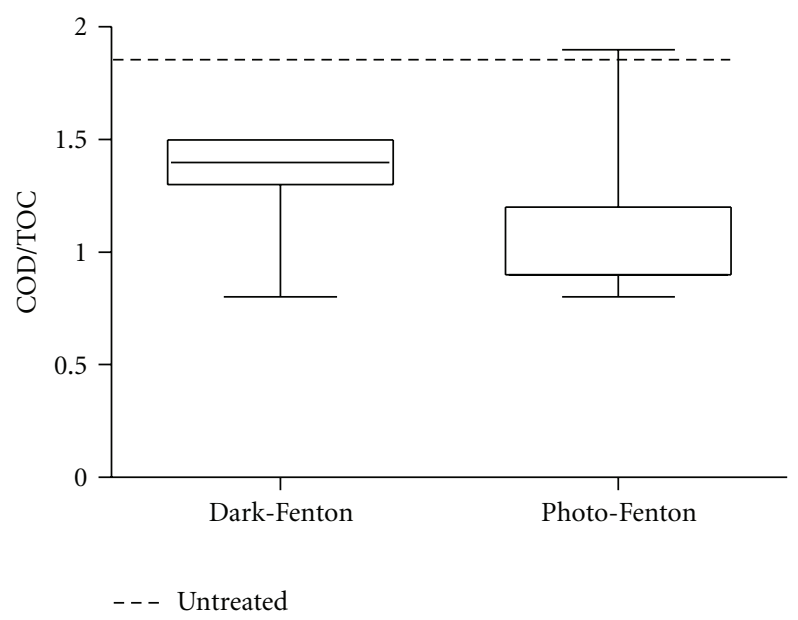

(d)

Figure 3: Boxplots built up with data from COD and TOC values obtained with dark-Fenton and photo-Fenton treatments. (a) COD reduction (in \%) with both treatments; (b) TOC reduction (in \%) with both treatments; (c) increase (in \%) in the percentage of COD and TOC reduction by photo-Fenton compared to dark-Fenton; (d) changes in COD/TOC ratio due to different treatments.

3.1.3. Oxidation and Mineralisation. The results have shown that the COD and TOC values after both dark- and photoFenton treatments were considerably different as indicated by the COD/TOC ratios (Figure $3(\mathrm{~d})$ ). There was no significant difference in $\mathrm{COD} / \mathrm{TOC}$ ratios when comparing photo-Fenton and dark-Fenton; however, COD/TOC ratios decreased after treatment. As illustrated in Figure 4, whereas negative correlations were found between COD and TOC reduction (in \%) and COD/TOC ratio $\left(R^{2}=0.86\right.$ and 0.62 , resp.) for the dark-Fenton experiments, only COD removal (in \%) was correlated with COD/TOC ratio $\left(R^{2}=\right.$ $0.92)$ in the photo-Fenton investigation. The correlation between TOC removal (in \%) and COD/TOC for photoFenton had coefficient of determination as low as $R^{2}=0.18$. These results suggest that the remaining organic compounds measured as TOC were very recalcitrant and difficult to degrade as indicated by very low COD/TOC ratios after these treatments, and even with higher reductions of COD, the TOC value was not lowered. Previous studies have reported that a COD/TOC ratio below 1.3 indicates that that residual organic carbon was mostly related to refractory organic compounds [16].

Unlike the COD value that is related to organicallybound and inorganic constituents [39], TOC is independent of the oxidation state of the organic matter and only measures organic carbon converted to $\mathrm{CO}_{2}$ [40], suggesting that changes observed in the $\mathrm{COD} / \mathrm{TOC}$ ratio can be related to the degree of changes in the structure of the organic compounds after oxidation. Figure 5 shows the AOS values before and after the treatment with dark-Fenton and photoFenton. It was found that by the end of the photo-Fenton treatment, the oxidation states were higher in comparison to those after the dark-Fenton treatment, confirming the stronger oxidation (higher reduction efficiency for COD and TOC) with photo-Fenton and suggesting the yield of different end products. Regarding the oxidation states in the dark-Fenton, the AOS value in the run 1.9 was considerably higher in comparison to the raw wastewater and to other dark-Fenton treatments reaching AOS value approximately as high as those obtained after the photo-Fenton process. 


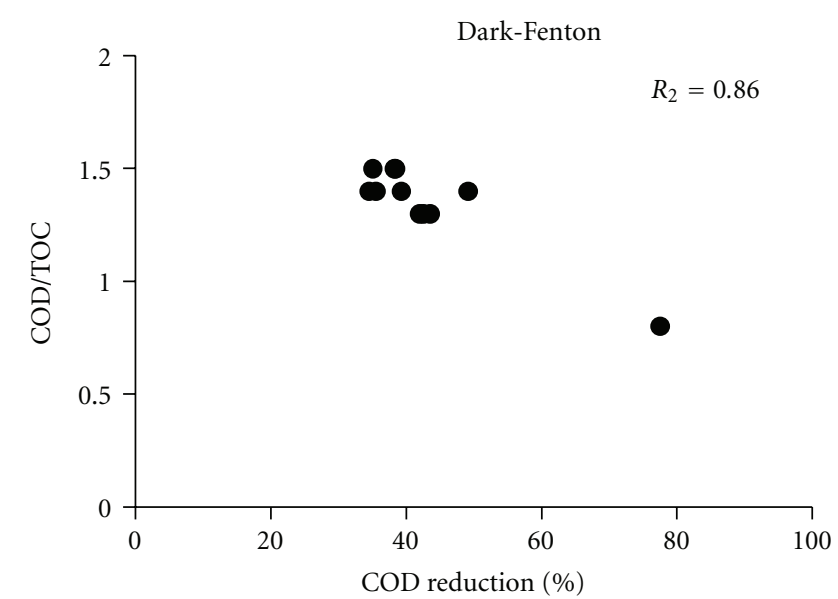

(a)

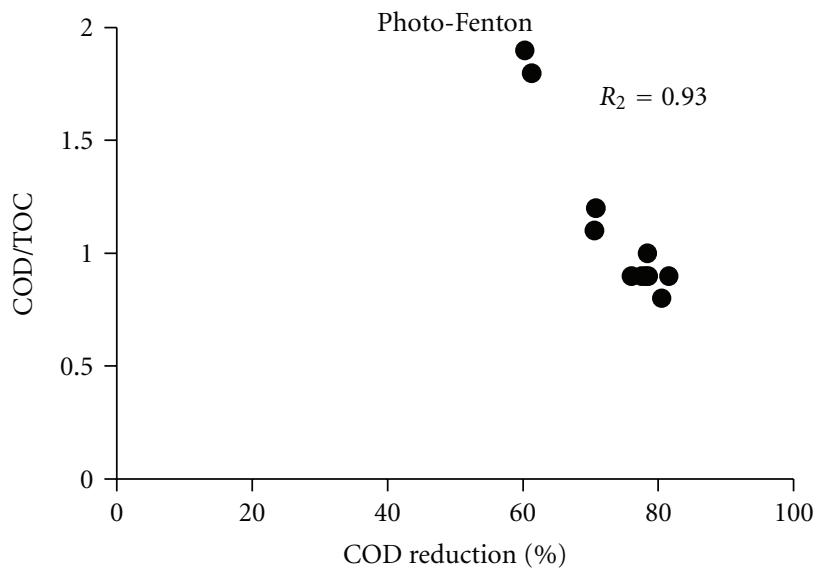

(c)

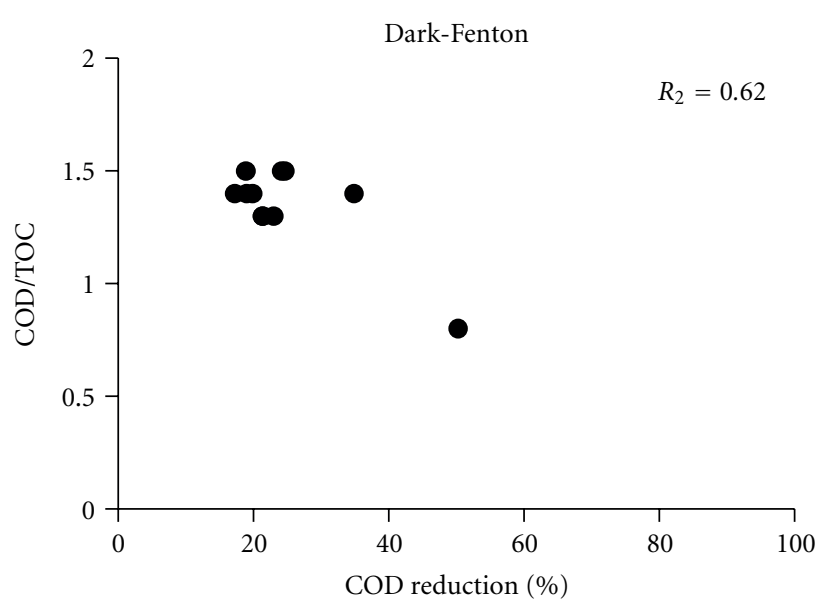

(b)

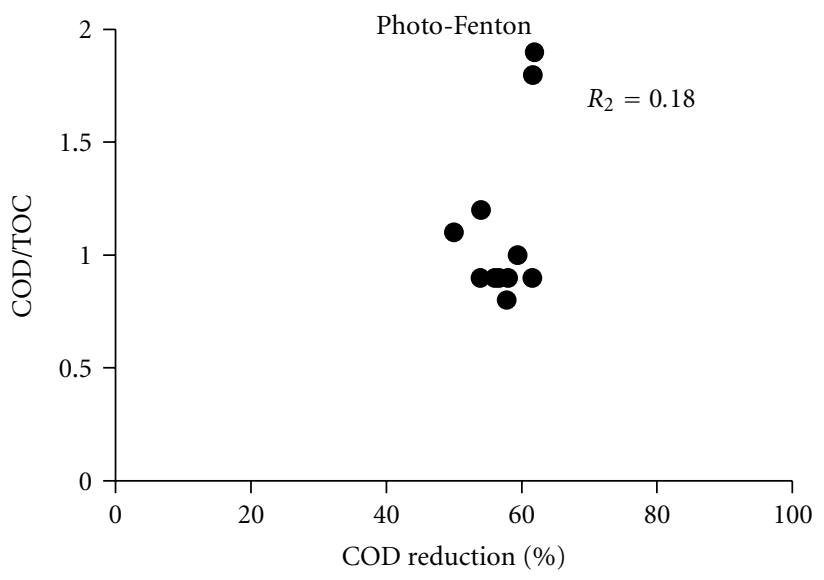

(d)

Figure 4: Correlation between COD and TOC reductions (in \%) and COD/TOC ratios obtained with different dark- and photo-Fenton treatment setups.

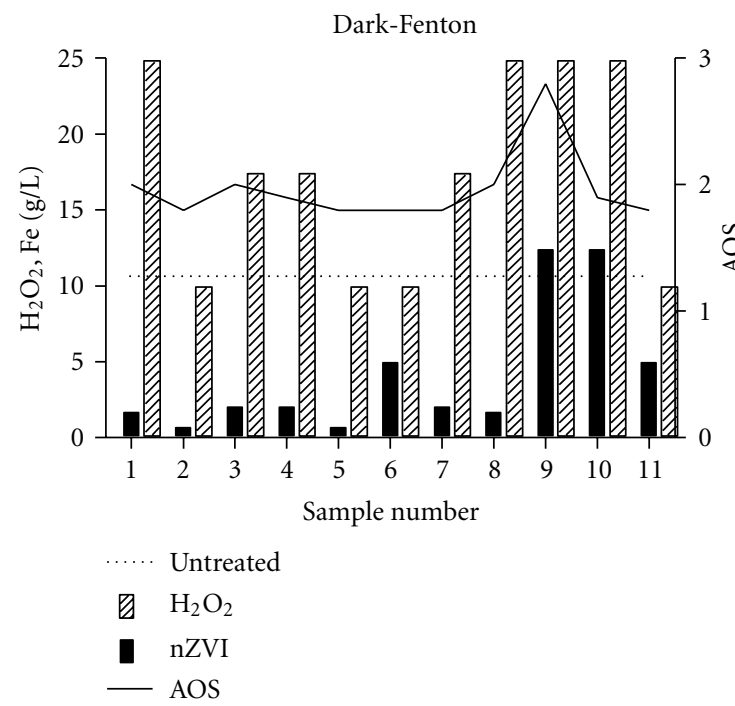

(a)

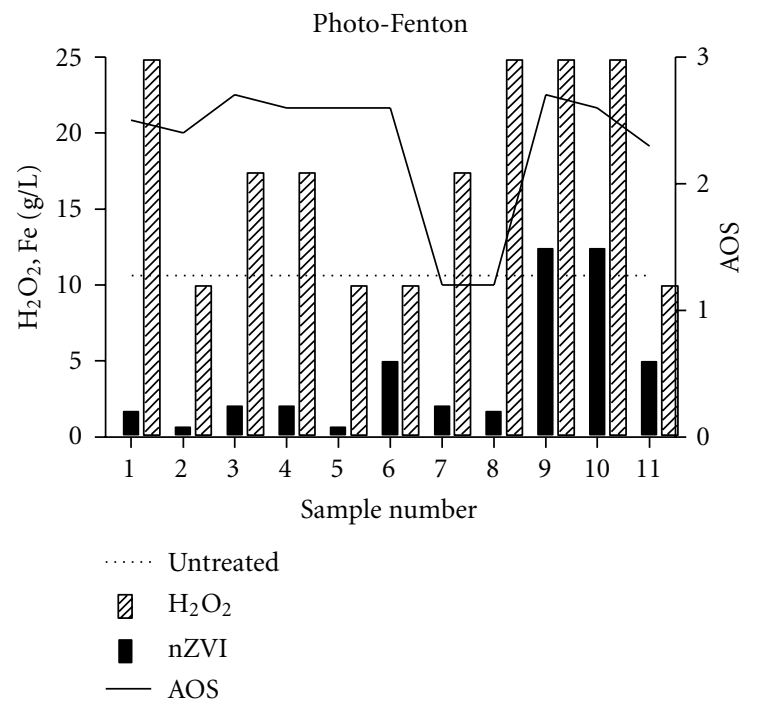

(b)

FIGURE 5: Amounts of reagents (g/L) and the AOS values obtained after each run/treatment. 
TABLE 5: Results of statistical analyses of independent variables.

\begin{tabular}{lcccccccc}
\hline & \multicolumn{3}{c}{ Dark-Fenton } & \multicolumn{4}{c}{ Photo-Fenton } \\
& \multicolumn{3}{c}{ COD reduction } & \multicolumn{2}{c}{ TOC reduction } & \multicolumn{2}{c}{ COD reduction } & \multicolumn{2}{c}{ TOC reduction } \\
Term & Effect & $P$ & Effect & $P$ & Effect & $P$ & Effect & $P$ \\
\hline Constant & & 0.00 & & 0.00 & & 0.00 & & 0 \\
$\mathrm{H}_{2} \mathrm{O}_{2}$ : COD Ratio & 17.3 & 0.01 & 12.4 & 0.02 & 0.9 & 0.91 & 6.8 & 0.07 \\
$\mathrm{H}_{2} \mathrm{O}_{2}$ : nZVI Ratio & -11.0 & 0.02 & -12.0 & 0.02 & -5.0 & 0.57 & 0.0 & 0.99 \\
Doses & 6.8 & 0.04 & 3.3 & 0.12 & -0.7 & 0.94 & 3.0 & 0.24 \\
$\mathrm{H}_{2} \mathrm{O}_{2}:$ COD Ratio $* \mathrm{H}_{2} \mathrm{O}_{2}:$ nZVI Ratio & -9.3 & 0.02 & -8.4 & 0.03 & -5.7 & 0.52 & 0.9 & 0.68 \\
$\mathrm{H}_{2} \mathrm{O}_{2}$ : COD Ratio $*$ Dose & 7.8 & 0.03 & 5.2 & 0.08 & -6.8 & 0.46 & 0.0 & 0.99 \\
$\mathrm{H}_{2} \mathrm{O}_{2}:$ nZVI Ratio $*$ Dose & -5.8 & 0.05 & -1.6 & 0.40 & -4.9 & 0.58 & 1.2 & 0.57 \\
$\mathrm{H}_{2} \mathrm{O}_{2}:$ COD Ratio $* \mathrm{H}_{2} \mathrm{O}_{2}:$ nZVI Ratio $*$ Dose & -8.0 & 0.02 & -5.3 & 0.07 & -5.7 & 0.52 & -1.8 & 0.43 \\
$\mathrm{Ct} \mathrm{Pt}$ & & 0.07 & & 0.01 & & 0.91 & & 0.39 \\
\hline
\end{tabular}

According to Figure 5, with the exception of runs 2.7 and 2.8, AOS values after the photo-Fenton treatments were approximately +3 in all remaining runs suggesting that the oxidised chemical nature of most of the photo-Fenton treatments reached a stable AOS value and even though the treatment was to be continued, intermediates with higher oxidation state would not be formed. At the moment that AOS stabilizes, the chemical treatment is only mineralizing organic contaminants, but with no partial oxidation [41]. This together with the fact that the difference between the COD and TOC after treatment was considerably reduced by the photo-Fenton treatment (paired $t$-test, $P<0.05$ ) indicates that a more complete reduction of the organic material was achieved when applying the photo-Fenton process. An increase in AOS during the treatment as observed in the current study, particularly for the photo-Fenton treatments, has been related to an increase in biodegradability [41] and reduction of toxicity [38].

This was confirmed by the fact that the reduction (in $\%$ ) obtained with photo-Fenton is greater for TOC than for COD (paired $t$-test, $P<0.05$ ), (Figure 3(c)). UV irradiation might have been responsible, for instance, for breaking down large aromatic molecules into aliphatic carbon chains, besides its effect on recycling $\mathrm{Fe}^{3+}$ back to $\mathrm{Fe}^{2+}[20]$.

3.1.4. Cost Effectiveness. Even though economic feasibility was not the focus of this investigation, one can mention that the main costs involved in the studied processes are related to the nZVI, the oxidizing agent $\mathrm{H}_{2} \mathrm{O}_{2}$, and the energy consumption of the UV-lamp. Photo-Fenton is reasonably more expensive than dark-Fenton treatment due to the use of a UV-lamp. However, the results have shown that when considering the overall treatment efficiency of both Fenton and photo-Fenton, the additional costs related to the UVlamp could be compensated by the less amounts of nZVI to achieve high COD and TOC reduction \%. Furthermore, the use of UV energy has brought advantages since it widened the range of reactant concentrations that could be used and still achieve very satisfactory treatment performances, making reasonable to state that is the less the amount of reactants, the more economically feasible the treatment becomes. Such advantage becomes very important in a full scale plant, where the concentration of pollutants in the raw wastewater can vary, which would require the use of different concentrations of reactants. A clear example is the run 2.5 (Table 4), which had the most satisfactory performance observed with the photo-Fenton treatment. In run 2.5 with the lowest reactant concentrations, COD and TOC reductions of $78 \%$ and $56 \%$, respectively, were achieved, making this the most economically feasible option in this study.

3.2. Effect of Independent Variables. The effects of the independent variables $\left(\mathrm{H}_{2} \mathrm{O}_{2}\right.$ : $\mathrm{COD} ; \mathrm{H}_{2} \mathrm{O}_{2}$ : nZVI and dosing mode) and the interaction among them on the COD and TOC removal (in \%) were obtained based on the data from the full-factorial design as shown in Table 5 . Whereas all factors and respective two-way and three-way interactions had significant effects on the COD and TOC removal efficiency with dark-Fenton process $(P<0.05)$, no significance was found in the case of photo-Fenton (Table 5). Reasonably, $\mathrm{H}_{2} \mathrm{O}_{2}$ : COD and $\mathrm{H}_{2} \mathrm{O}_{2}$ : nZVI ratios were the factors that played the most important roles considering dark-Fenton treatment. Reasonably, negative values were obtained for the effects caused by the $\mathrm{H}_{2} \mathrm{O}_{2}$ : nZVI ratios on COD and TOC reduction in \% with dark-Fenton, since the lower the ratio is, the higher the treatment efficiency will be as previously discussed. The results have shown that by reducing the $\mathrm{H}_{2} \mathrm{O}_{2}$ :nZVI ratio from $15: 1$ down to $2: 1$, the reductions (in \%) of COD and TOC could be increased by $11 \%$ and $12 \%$, respectively. The significant effect of the dosing mode on both COD and TOC reductions suggests that when large amounts of reactants are added at once, the treatment performance was not increased due to scavenging $[37,42]$. On the other hand, by splitting the doses of the reactants into several steps, scavenging was avoided, an effect that has been described only very few previous studies [42, 43]. The results have shown that the studied factors and levels applied did not play any significant role in the case of photoFenton experiments. These results suggest that the long UVexposure time has eliminated large differences in the results or by combining chemical oxidation and UV irradiation other factors might be involved. 


\section{Conclusions}

The following conclusions can be withdrawn from this investigation:

a. COD and TOC can effectively be reduced by at least $80 \%$ and $60 \%$, respectively, from recalcitrant industrial wastewater from the wood industry using photoFenton;

b. the most effective treatment setup for dark-Fenton was achieved with $\mathrm{H}_{2} \mathrm{O}_{2}$ : COD ratio of $5: 1$, $\mathrm{H}_{2} \mathrm{O}_{2}$ : nZVI ratio of $2: 1$ and with a dose mode that supplies the reactants in 3 equal aliquots added at equal time intervals;

c. the most effective treatment setup for photoFenton was obtained with $\mathrm{H}_{2} \mathrm{O}_{2}$ : COD ratio of $5: 1$, $\mathrm{H}_{2} \mathrm{O}_{2}$ : nZVI ratio of $2: 1$, supplying the reactants in 3 equal aliquots added at equal time intervals; however, treatments close to the stoichiometry value (2.125) preformed almost as good;

d. there was a significant increase in the mineralization when combining UV with Fenton (photo-Fenton).

\section{Acknowledgments}

The financial support to the research project from the Swedish Knowledge Foundation (KK-Stiftelsen), the European Regional Development Fund, and the industry AB Gustaf Kähr is acknowledged.

\section{References}

[1] F. Kaczala, M. Marques, and W. Hogland, "Biotreatability of wastewater generated during machinery washing in a woodbased industry: COD, formaldehyde and nitrogen removal," Bioresource Technology, vol. 101, no. 23, pp. 8975-8983, 2010.

[2] S. Laohaprapanon, M. Marques, and W. Hogland, "Removal of organic pollutants from wastewater using wood fly ash as a low-cost sorbent," Clean, vol. 38, no. 11, pp. 1055-1061, 2010.

[3] M. Krzemieniewski, M. Debowski, A. Dobrzynska, and M. Zielinski, "Chemical oxygen demand reduction of various wastewater types using magnetic field-assisted fenton reaction," Water Environment Research, vol. 76, no. 4, pp. 301-309, 2004.

[4] A. Kyriacou, K. E. Lasaridi, M. Kotsou, C. Balis, and G. Pilidis, "Combined bioremediation and advanced oxidation of green table olive processing wastewater," Process Biochemistry, vol. 40, no. 3-4, pp. 1401-1408, 2005.

[5] D. Suryaman, K. Hasegawa, and S. Kagaya, "Combined biological and photocatalytic treatment for the mineralization of phenol in water," Chemosphere, vol. 65, no. 11, pp. 25022506, 2006.

[6] I. Oller, S. Malato, J. A. Sánchez-Pérez, M. I. Maldonado, and R. Gassó, "Detoxification of wastewater containing five common pesticides by solar AOPs-biological coupled system," Catalysis Today, vol. 129, no. 1-2, pp. 69-78, 2007.

[7] W. K. Lafi, B. Shannak, M. Al-Shannag, Z. Al-Anber, and M. Al-Hasan, "Treatment of olive mill wastewater by combined advanced oxidation and biodegradation," Separation and Purification Technology, vol. 70, no. 2, pp. 141-146, 2009.
[8] O. Tunay et al., Chemical Oxidation Applications for Industrial Wastewaters, IWA, 2010.

[9] F. Torrades, S. Saiz, and J. A. García-Hortal, "Using central composite experimental design to optimize the degradation of black liquor by Fenton reagent," Desalination, vol. 268, no. 13, pp. 97-102, 2011.

[10] K. Choi and W. Lee, "Enhanced degradation of trichloroethylene in nano-scale zero-valent iron Fenton system with Cu(II)," Journal of Hazardous Materials, vol. 211-212, pp. 146153, 2012.

[11] M. I. Badawy, M. Y. Ghaly, and T. A. Gad-Allah, "Advanced oxidation processes for the removal of organophosphorus pesticides from wastewater," Desalination, vol. 194, no. 1-3, pp. 166-175, 2006.

[12] I. Arslan-Alaton Idil, A. B. Yalabik, and T. Olmez-Hanci, "Development of experimental design models to predict Photo-Fenton oxidation of a commercially important naphthalene sulfonate and its organic carbon content," Chemical Engineering Journal, vol. 165, no. 2, pp. 597-606, 2010.

[13] K. V. Padoley, S. N. Mudliar, S. K. Banerjee, S. C. Deshmukh, and R. A. Pandey, "Fenton oxidation: a pretreatment option for improved biological treatment of pyridine and 3cyanopyridine plant wastewater," Chemical Engineering Journal, vol. 166, no. 1, pp. 1-9, 2011.

[14] D. Hermosilla, N. Merayo, R. Ordóñez, and A. Blanco, "Optimization of conventional Fenton and ultraviolet-assisted oxidation processes for the treatment of reverse osmosis retentate from a paper mill," Waste Management, vol. 32, no. 6, pp. 1236-1243, 2012.

[15] P. Bautista, A. F. Mohedano, M. A. Gilarranz, J. A. Casas, and J. J. Rodriguez, "Application of Fenton oxidation to cosmetic wastewaters treatment," Journal of Hazardous Materials, vol. 143, no. 1-2, pp. 128-134, 2007.

[16] A. M. F. M. Guedes, L. M. P. Madeira, R. A. R. Boaventura, and C. A. V. Costa, "Fenton oxidation of cork cooking wastewater-overall kinetic analysis," Water Research, vol. 37, no. 13, pp. 3061-3069, 2003.

[17] M. Umar, H. A. Aziz, and M. S. Yusoff, "Trends in the use of Fenton, electro-Fenton and photo-Fenton for the treatment of landfill leachate," Waste Management, vol. 30, no. 11, pp. 2113-2121, 2010.

[18] P. Bautista, A. F. Mohedano, J. A. Casas, J. A. Zazo, and J. J. Rodriguez, "An overview of the application of Fenton oxidation to industrial wastewaters treatment," Journal of Chemical Technology and Biotechnology, vol. 83, no. 10, pp. 1323-1338, 2008.

[19] W. Z. Tang and R. Z. Chen, "Decolorization kinetics and mechanisms of commercial dyes by $\mathrm{H}_{2} \mathrm{O}_{2}$ /iron powder system," Chemosphere, vol. 32, no. 5, pp. 947-958, 1996.

[20] M. Tamimi, S. Qourzal, N. Barka, A. Assabbane, and Y. Ait-Ichou, "Methomyl degradation in aqueous solutions by Fenton's reagent and the photo-Fenton system," Separation and Purification Technology, vol. 61, no. 1, pp. 103-108, 2008.

[21] I. Arslan and I. A. Balcioglu, "Advanced oxidation of raw and biotreated textile industry wastewater with $\mathrm{O} 3, \mathrm{H}_{2} \mathrm{O}_{2} / \mathrm{UV}$ $\mathrm{C}$ and their sequential application," Journal of Chemical Technology \& Biotechnology, vol. 76, no. 1, pp. 53-60, 2001.

[22] B.-H. Moon, Y.-B. Park, and K.-H. Park, "Fenton oxidation of Orange II by pre-reduction using nanoscale zero-valent iron," Desalination, vol. 268, no. 1-3, pp. 249-252, 2011.

[23] M. Barreto-Rodrigues, F. T. Silva, and T. C. B. Paiva, "Combined zero-valent iron and fenton processes for the treatment of Brazilian TNT industry wastewater," Journal of Hazardous Materials, vol. 165, no. 1-3, pp. 1224-1228, 2009. 
[24] P. J. A. Borm, D. Robbins, S. Haubold et al., "The potential risks of nanomaterials: a review carried out for ECETOC," Particle and Fibre Toxicology, vol. 3, no. 1, article 11, 2006.

[25] R. A. Crane and T. B. Scott, "Nanoscale zero-valent iron: future prospects for an emerging water treatment technology," Journal of Hazardous Materials, vol. 211-212, pp. 112-125, 2012.

[26] S. Jagadevan, M. Jayamurthy, P. Dobson, and I. P. Thompson, "A novel hybrid nano zerovalent iron initiated oxidationbiological degradation approach for remediation of recalcitrant waste metalworking fluids," Water Research, vol. 46, no. 7, pp. 2395-2404, 2012.

[27] Q. J. Rasheed, K. Pandian, and K. Muthukumar, “Treatment of petroleum refinery wastewater by ultrasound-dispersed nanoscale zero-valent iron particles," Ultrasonics Sonochemistry, vol. 18, no. 5, pp. 1138-1142, 2011.

[28] F. Kaczala, M. Marques, and W. Hogland, "Lead and vanadium removal from a real industrial wastewater by gravitational settling/sedimentation and sorption onto Pinus sylvestris sawdust," Bioresource Technology, vol. 100, no. 1, pp. 235-243, 2009.

[29] S. Laohaprapanon, F. Kaczalaa, P. S. Salomonbc, M. Marquesad, and W. Hoglanda, "Wastewater generated during cleaning/washing procedures in a wood-floor industry: toxicity on the microalgae Desmodesmus subspicatus," Environmental Technology. In press.

[30] Z. Shiyun, Z. Xuesong, and L. Daotang, "Ozonation of naphthalene sulfonic acids in aqueous solutions. Part I: elimination of COD, TOC and increase of their biodegradability," Water Research, vol. 36, no. 5, pp. 1237-1243, 2002.

[31] V. Sarria, S. Kenfack, O. Guillod, and C. Pulgarin, "An innovative coupled solar-biological system at field pilot scale for the treatment of biorecalcitrant pollutants," Journal of Photochemistry and Photobiology A, vol. 159, no. 1, pp. 89-99, 2003.

[32] F. J. Benitez, F. J. Real, J. L. Acero, C. Garcia, and E. M. Llanos, "Kinetics of phenylurea herbicides oxidation by Fenton and photo-Fenton processes," Journal of Chemical Technology and Biotechnology, vol. 82, no. 1, pp. 65-73, 2007.

[33] H. Kusic, N. Koprivanac, and L. Srsan, "Azo dye degradation using Fenton type processes assisted by UV irradiation: a kinetic study," Journal of Photochemistry and Photobiology A, vol. 181, no. 2-3, pp. 195-202, 2006.

[34] C.-C. Su, M. Pukdee-Asab, C. Ratanatamskulb, and M.-C. $\mathrm{Lu}$, "Effect of operating parameters on decolorization and COD removal of three reactive dyes by Fenton's reagent using fluidized-bed reactor," Desalination, vol. 278, no. 1-3, pp. 211218, 2011.

[35] X. Zhu, J. Tian, R. Liu, and L. Chen, "Optimization of Fenton and electro-Fenton oxidation of biologically treated coking wastewater using response surface methodology," Separation and Purification Technology, vol. 81, no. 3, pp. 444-450, 2011.

[36] M. S. Lucas and J. A. Peres, "Removal of COD from olive mill wastewater by Fenton's reagent: kinetic study," Journal of Hazardous Materials, vol. 168, no. 2-3, pp. 1253-1259, 2009.

[37] C. T. Benatti, C. R. G. Tavares, and T. A. Guedes, "Optimization of Fenton's oxidation of chemical laboratory wastewaters using the response surface methodology," Journal of Environmental Management, vol. 80, no. 1, pp. 66-74, 2006.

[38] E. Elmolla and M. Chaudhuri, "Optimization of Fenton process for treatment of amoxicillin, ampicillin and cloxacillin antibiotics in aqueous solution," Journal of Hazardous Materials, vol. 170, no. 2-3, pp. 666-672, 2009.
[39] H. Zhang, J. C. Heung, and C. P. Huang, "Optimization of Fenton process for the treatment of landfill leachate," Journal of Hazardous Materials, vol. 125, no. 1-3, pp. 166-174, 2005.

[40] D. R. Medley and E. L. Stover, "Effects of ozone on the biodegradability of biorefractory pollutants," Journal of the Water Pollution Control Federation, vol. 55, no. 5, pp. 489-494, 1983.

[41] C. Sirtori, A. Zapata, I. Oller, W. Gernjak, A. Agüera, and S. Malato, "Decontamination industrial pharmaceutical wastewater by combining solar photo-Fenton and biological treatment," Water Research, vol. 43, no. 3, pp. 661-668, 2009.

[42] Y. Deng and J. D. Englehardt, "Treatment of landfill leachate by the Fenton process," Water Research, vol. 40, no. 20, pp. 36833694, 2006.

[43] R. C. Martins, A. F. Rossi, and R. M. Quinta-Ferreira, "Fenton's oxidation process for phenolic wastewater remediation and biodegradability enhancement," Journal of Hazardous Materials, vol. 180, no. 1-3, pp. 716-721, 2010. 


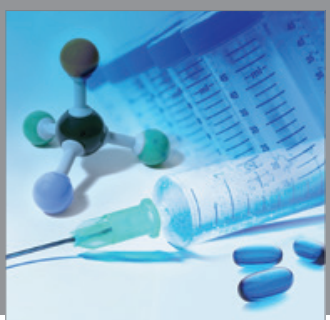

International Journal of

Medicinal Chemistry

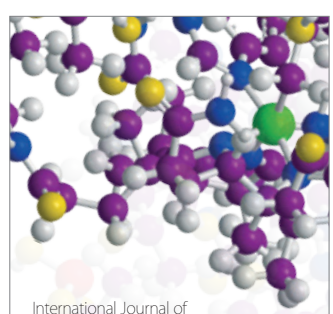

Carbohydrate Chemistry

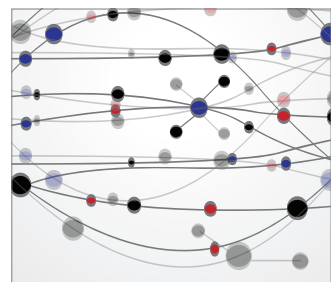

The Scientific World Journal
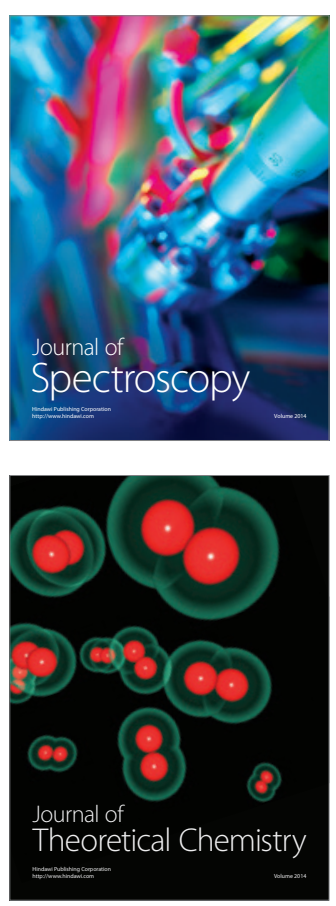
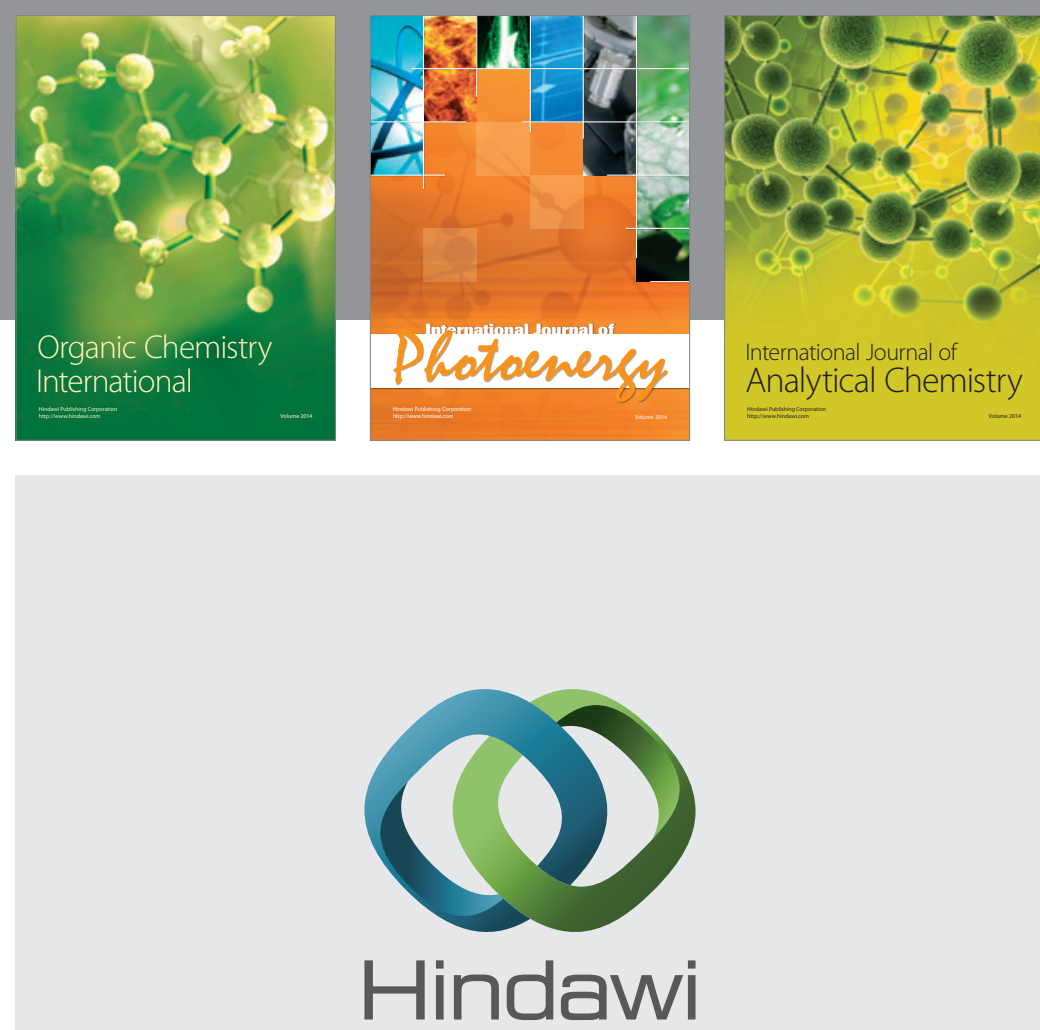

Submit your manuscripts at

http://www.hindawi.com
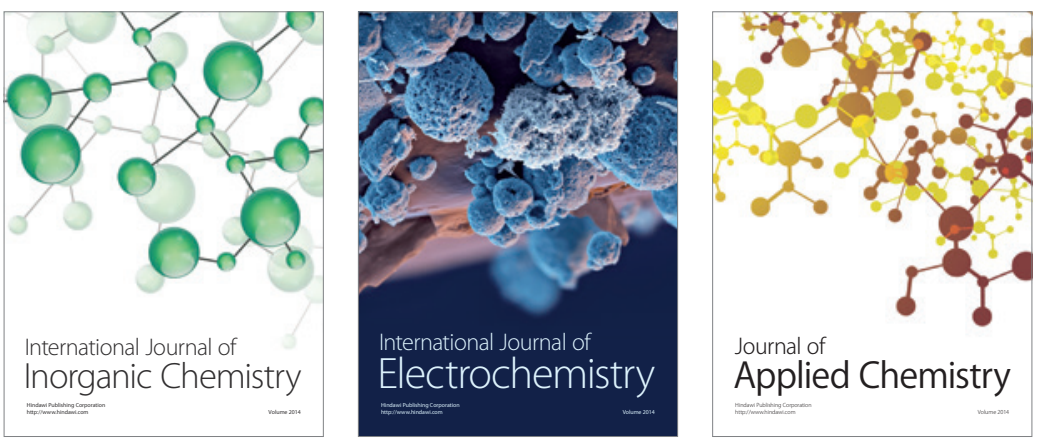

Journal of

Applied Chemistry
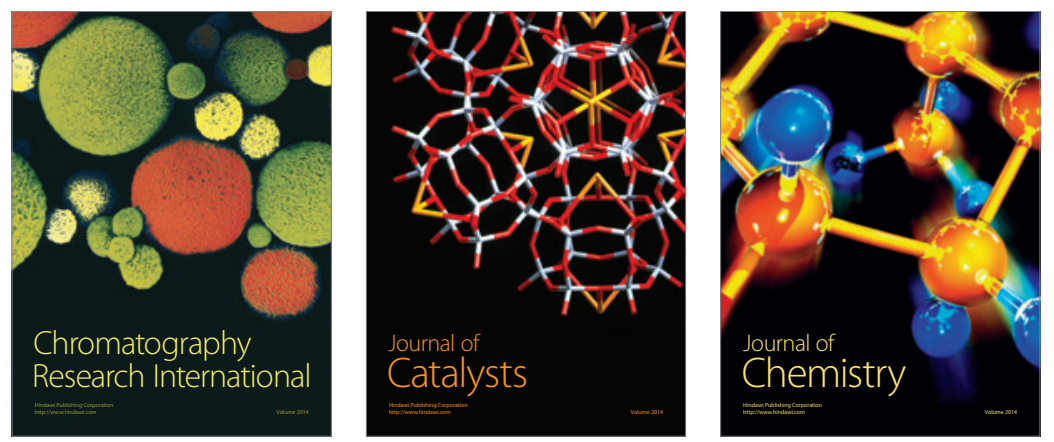
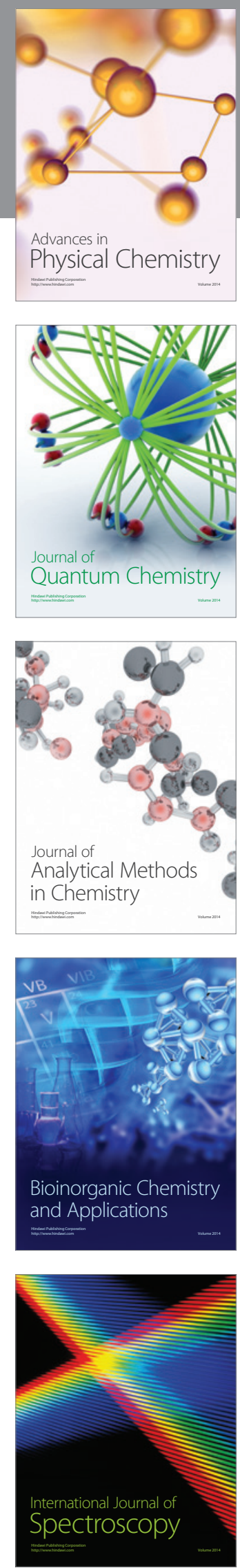